\title{
Effect of nicotinamide treatment on the residual insulin secretion in Type 1 (insulin-dependent) diabetic patients
}

\author{
P. Vague, R. Picq, M. Bernal, V.Lassmann-Vague and B. Vialettes \\ Service de Diabétologie, Centre Hospital Universitaire Timone, Marseille, France
}

\begin{abstract}
Summary. In vivo and in vitro experiments have shown that nicotinamide enhances the regeneration of rat $\mathbf{B}$ cells. Nicotinamide has been administered to human subjects at a dose of $3 \mathrm{~g} /$ day for more than one year without any serious side effects. A trial was conducted to study if nicotinamide could protect B cells in Type I (insulin-dependent) diabetic patients with established diabetes, but still with residual insulin secretion, the latter being evaluated throughout the study period. A randomized double-blind study was carried out on 26 Type I diabetic patients aged 15 to 40 years who had been treated with insulin for 1 to 5 years but who had a residual insulin secretion characterized by a glucagon stimulated C-peptide level higher than $0.1 \mathrm{nmol} / 1$. They were given either $3 \mathrm{~g} /$ day of nicotinamide or a placebo for nine months. At baseline the treated and control groups did not differ according to age, diabetes duration, insulin dose, $\mathrm{HbA}_{1 \mathrm{c}}$ or C-peptide levels. Three patients dropped out of the study. At 9 months there were no significant changes in the insulin doses required. However, $\mathrm{HbA}_{1 \mathrm{c}}$ rose in the control group $(8.1 \pm 0.4$ vs
\end{abstract}

$9.8 \pm 0.5 \%, p<0.05)$ but not in the nicotinamide treated group $(7.5 \pm 0.5$ vs $6.9 \pm 0.4 \%)$. Insulin secretion deteriorated in the control patients (fasting C-peptide: $0.28 \pm 0.05$ vs $0.12 \pm 0.03 \mathrm{nmol} / \mathrm{l}, \quad p<0.05$; post glucagon C-peptide: $0.34 \pm 0.07$ vs $0.14 \pm 0.02, p<0.05$ ) but not in the treated patients (fasting C-peptide: $0.22 \pm 0.04$ vs $0.24 \pm 0.05 \mathrm{nmol} / 1$; post glucagon C-peptide: $0.30 \pm 0.04$ vs $0.33 \pm 0.07$ ). At six and nine months, fasting and stimulated C-peptide were higher in the treated than in the non-treated group. The C-peptide response to a meal test gradually declined in the placebo group, whereas it was stable in the nicotinamide treated group. No serious side effects were noted; in particular, hepatic function and plasma lipid content remained unchanged. These results suggest that nicotinamide treatment may protect residual Bcell function in Type 1 diabetes; but further studies are needed to assess the clinical implications of such treatment.

Key words: Nicotinamide, Type 1 (Insulin-dependent) diabetes, C-peptide, residual insulin secretion.
The natural course of Type 1 (insulin-dependent) diabetes is characterized by a progressive destruction of insulin-secreting cells resulting from an autoimmune disorder [1]. Possibly this process of destruction could be halted either by stimulating regeneration of $\mathrm{B}$ cells or, by increasing their resistance. Animal experiments have demonstrated that in high doses nicotinamide $(\mathrm{N})$, an inhibitor of poly (ADP - ribose) synthetase not only prevents the induction of diabetes by streptozotocin [2] but also favours the regeneration of B cells in partially pancreatectomized rats [3]. It slows or stops diabetes induced by immune processes i.e. diabetes in NOD mice [4] or insulitis-related diabetes induced by multiple low dose administration of streptozotocin [5] and inhibits rejection of islet cell grafts in NOD mice [6]. N or its precursor, nicotinic acid, have been administered to humans at relatively high doses ( $3 \mathrm{~g} /$ day or more) for pro- longed periods of more than one year in attempts to improve schizophrenia [7,8], slow the progression of coronary artery disease [9] or treat annular granuloma [10] and no serious adverse effects have been reported. We have previously prescribed $3 \mathrm{~g}$ of $\mathrm{N}$ to newly diagnosed Type 1 diabetic patients for periods of up to 18 months and observed that remissions in these patients were more frequent and longer than in patients receiving a placebo [11]. Spontaneous partial recovery of insulin secretion as assessed by C-peptide level is common in diabetic patients at the start of insulin treatment $[12,13]$ however, thus making it difficult to assert any therapeutic effect. However, 6 months after the clinical onset of the disease the insulin secretory capacity decreases regularly [14-16]. The purpose of this double blind controlled study was to determine the effect of oral nicotinamide on residual insulin secretion in 


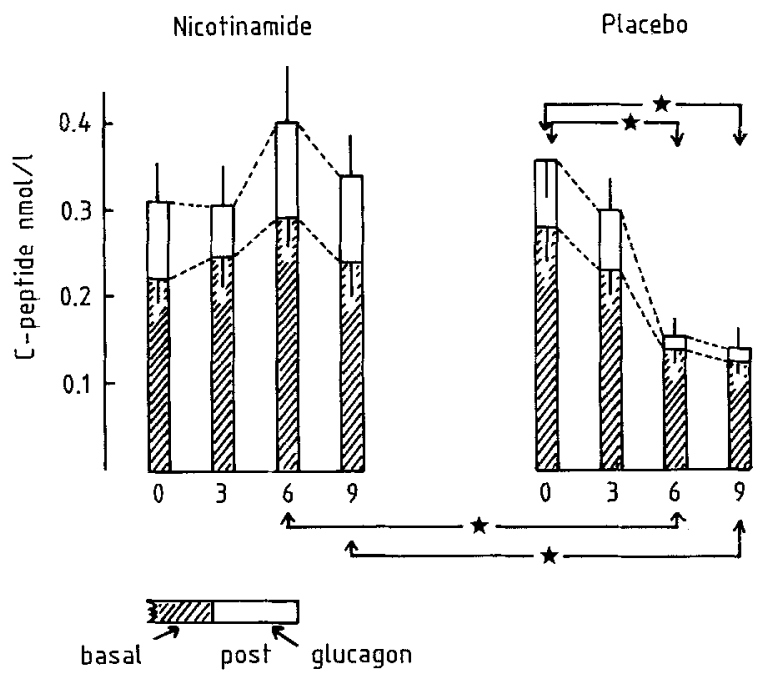

Fig. 1. Basal (hatched columns) and glucagon stimulated (open columns) in the nicotinamide and the placebo treated groups at entry 3 , 6 and 9 months. Vertical bars indicate S. E.M.; Asterisks denote significance at the 0.05 level between arrows

Type 1 diabetic patients after the honeymoon period. If a protective effect could be demonstrated, the use of $\mathrm{N}$ in combination with, or following the use of immunosuppressive agents could be envisaged.

\section{Patients and methods}

\section{Inclusion criteria}

In order to select Type 1 diabetic patients, after their transient honeymoon period but still with some residual insulin secretion, the following inclusion criteria were selected:

- unequivocally confirmed Type 1 diabetes (presentation at diagnosis including loss of weight, polyuria, gross ketonuria and hyperglycaemia and evident need for insulin therapy) diagnosed between the ages of 15 and 40 years;

- insulin treatment lasting 1 to 5 years;

- residual insulin secretion as demonstrated by C-peptide level higher than $0.1 \mathrm{nmol} / 15 \mathrm{~min}$ after iv injection of $1 \mathrm{mg}$ of glucagon;

- no history of hepatitis.

Table 1. Baseline characteristic of the patients used in the study

\begin{tabular}{lll}
\hline & $\begin{array}{l}\text { Nicotinamide } \\
\text { group }\end{array}$ & $\begin{array}{l}\text { Placebo } \\
\text { group }\end{array}$ \\
\hline Number & 11 & 12 \\
Male/female & $9 / 2$ & $8 / 4$ \\
HLA DR 3 and/or 4 & 8 & 8 \\
Age (years) & $29.8 \pm 7.3$ & $26.8 \pm 6.2$ \\
$\quad$ range & $25-38$ & $18-39$ \\
Diabetes duration (months) & $28.2 \pm 14$ & $25.8 \pm 10.3$ \\
$\quad$ range & $12-49$ & $15-57$ \\
Body mass index (kg/m ${ }^{2}$ ) & $21.2 \pm 1.7$ & $21.8 \pm 1.9$ \\
Insulin dose (IU/day) & $34 \pm 16.9$ & $34.2 \pm 17.4$ \\
HbA Ic $^{0 / 0}$ & $7.51+1.6$ & $8.08+1.3$ \\
Fasting C-Peptide (nmol/l) & $0.22 \pm 0.12$ & $0.28 \pm 0.15$ \\
Glucagon stimulated C-peptide & $0.30 \pm 0.16$ & $0.34 \pm 0.2$ \\
\hline
\end{tabular}

Values are mean \pm S. D.
All patients were regularly followed in our department, treated by two insulin injections per day and gave their informed consent. Children under the age of 15 were excluded because they could not give a personal informed consent. The study protocol was approved by the Ethics Committee of the Marseille Medical School.

\section{Experimental protocol}

In addition to the usual insulin treatment consisting of two daily injections of intermediate acting insulin (or a combination of regular and intermediate insulin), and no other medication, patients were randomly allocated to treatment by two $0.5 \mathrm{~g}$ nicotinamide or placebo tablets three times per day (3ig) Astra-France Laboratoire, Nanterre, France) and the follow-up was double blind. The patients measured their capillary glycaemia twice a day before injection and 5 times a day at least once a week and were advised to use the lowest insulin dose necessary to maintain proper glycaemic control. Check-ups were scheduled every three months or more often if necessary. Compliance was ascertained by examination of the pills remaining in the bottle at each visit.

At zero, three, six and nine months, the following parameters were measured in addition to clinical examination: $\mathrm{HbA}_{1 \mathrm{c}}$, glycaemia and C-peptide before, then 5 and $10 \mathrm{~min}$ after, $i$. $v$. injection of $1 \mathrm{mg}$ of glucagon. Liver function and lipid levels were also investigated. The day after these tests C-peptide was measured before, then $30,60,90$, and 120 min after a standard breakfast test comprising $500 \mathrm{kcal}$ made up of $53 \%$ carbohydrate, $29 \%$ lipid and $18 \%$ protid. The morning s.c. insulin injection was given $5 \mathrm{~min}$ before breakfast.

\section{Laboratory data}

Plasma glucose was measured by the glucose oxydase method in a Technicon autoanalyser, $\mathrm{HbA}_{1 \mathrm{c}}$ by chromatography on a cation exchange resin at $23^{\circ} \mathrm{C}$ (Biorad, Hercules, Calif, USA), and plasma Cpeptide by radioimmunoassay according to Kaneko [17] and using a commercially available kit (BYK Mallinkrodt, Evry, France). Sera were not extracted before assaying $\mathrm{C}$-peptide because they contained negligible amounts of insulin (pro-insulin) antibodies has estimated by the binding of ${ }^{125} \mathrm{I}$ (Tyr-A14) insulin (Novo, Bagsvaerd, Denmark). In fact, all the patients had always been treated by monocomponent insulin. In our laboratory the lower limit of sensitivity is $0.03 \mathrm{~nm} / 1$; the inter-assay variation coefficient $4.8 \%$, and the intra-assay variation coefficient $3.1 \%$. HLA DR antigens were determined by standard lymphocytotoxicity method and islet cell antibodies (ICA) by indirect immunofluorescence on unfixed human pancreas. Plasma lipid and hepatic function tests were assessed by routine techniques in the same laboratory throughout the study.

\section{Statistical analysis}

As the sample size was small, and the data not normally distributed, two-tailed, non-parametric Wilcoxon signed rank test for paired data was used for intragroup comparison, and two-tailed Mann Whitney test for comparison between groups. A $p$ value lower than 0.05 was considered as statistically significant.

\section{Results}

Twenty-six patients entered this study. Two patients in the nicotinamide group and one in the placebo group, dropped out for different reasons, i.e. wish for pregnancy, relocation, and recurrent diarrhoea. At baseline 
(Table 1) the two groups did not differ with regard to clinical findings, control of diabetes, insulin dose, and fasting or stimulated (glucagon or meal) C-peptide levels. At the time of entry into the study, i. e. an average of two years after diagnosis of diabetes, islet cell antibodies persisted in $40 \%(9 / 23)$ of the patients equally in the two groups. ICA determinations at the time of diagnosis of diabetes were available for 16 patients only and positive in 11.

The mean body mass index $\left(\mathrm{kg} / \mathrm{m}^{2}\right)$ did not vary during the study in either group; it was 21.2 and 21.4 at the beginning and end respectively in the nicotinamide group and 21.5 and 21.7 in the placebo group. No change in $\mathrm{HbA}_{1 \mathrm{c}}$ values was observed in the nicotinamide group. In the placebo group $\mathrm{HbA}_{1 \mathrm{c}}$ values were higher at 6 and 9 months (Table 2) and this difference was significantly different on both occasions $(p<0.05)$. The mean of the two fasting glycaemia measurements performed before the glucagon test and the breakfast test every three months did not change significantly during the study period. The insulin dose level showed a downward tendency in the nicotinamide group and an upward tendency in the placebo group but the difference was not statistically significant at any time during the study (Table 2).

Figure 1 shows the fasting and glucagon-stimulated C-peptide values recorded in the two patient groups. No significant change in these values was observed in the nicotinamide group in the 9 months of study. Conversely, in the placebo group, both fasting and stimulated C-peptide values declined gradually. (Fig.1, right). Compared to baseline values, basal C-peptide was lower at six months $(p=0.02)$ and at 9 months $(p=0.01)$. The same was observed for glucagon stimulated C-peptide at $6(p=0.03)$ and 9 months $(p=0.01)$. When the treated and placebo groups were compared both basal and stimulated C-peptide differed significantly at 6 months ( $p=0.05$ and 0.03 respectively) and at 9 months ( $p=0.02$ and 0.03 respectively). Individual C-peptide values are shown in Figure 2. Regardless of its initial level, C-peptide dropped steadily in the placebo group. However, this parameter remained stable in the nicotinamide group. This stability does not seem to depend on the initial C-peptide level. Similarly, the C-peptide response to the test meal persisted throughout the study in patients treated with nicotinamide, whereas this response gradually faded in

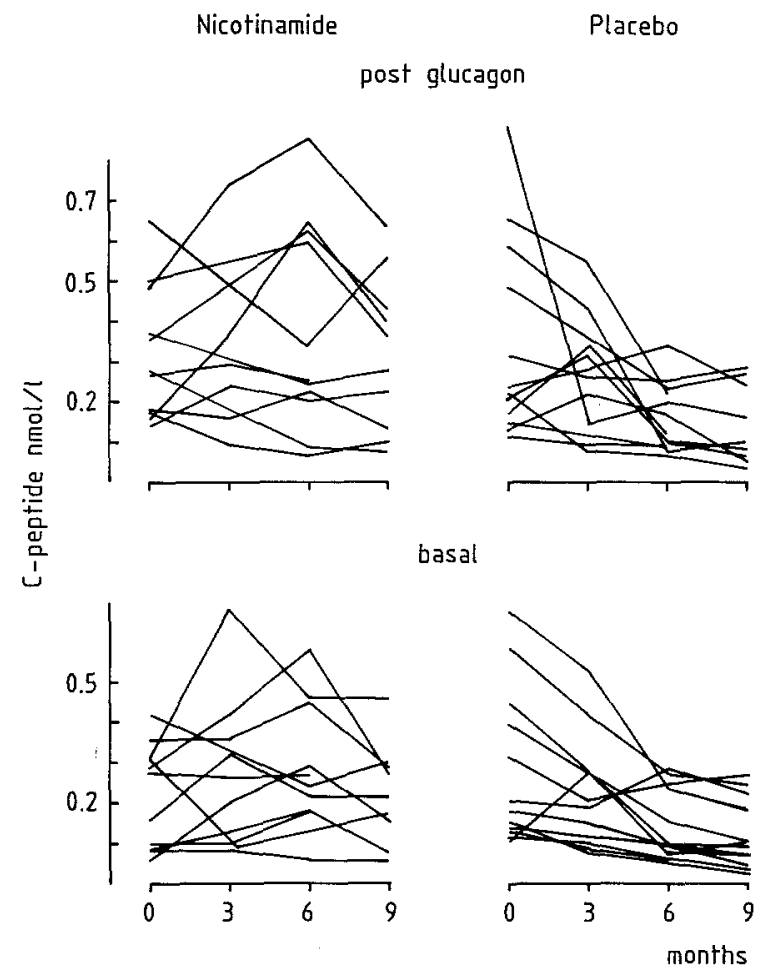

Fig. 2. Individual values of basal and glucagon stimulated C-peptide levels in the nicotinamide and placebo treated groups during the follow up

patients given the placebo. The difference between the two groups was significant at the sixth and ninth months (Fig. 3). It must be pointed out that plasma glucose both fasting and after the meal was similar between the two groups.

As far as side effects are concerned, headaches were recorded twice, once in each group, and weariness three times (twice in the nicotinamide group). These symptoms did not require discontinuation of treatment. One patient in the nicotinamide group suffered recurrent diarrhoea and had to be dropped from the study after 5 months. Liver function was normal at baseline and remained so throughout the study. Normal levels were also recorded for plasma lipid and apoprotein A1 and B. Another noteworthy finding is that total cholesterol did not decrease. The plasma levels of uric acid and creatinine did not change.

Table 2. Plasma glucose, $\mathrm{HbA}_{1 \mathrm{c}}$ and insulin dose (Mean \pm S.E. M.) at entry, and at 3,6 and 9 months in the two treatment groups

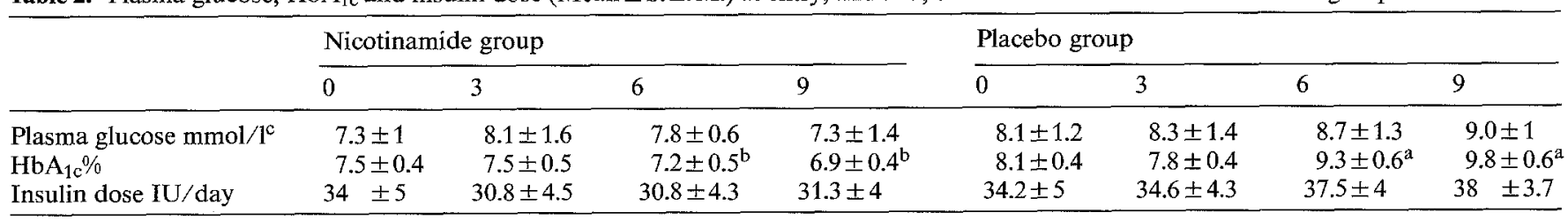

a Denotes significant difference at the $5 \%$ level with baseline value in the same group;

${ }^{b}$ Denotes significant difference at the $5 \%$ level with the placebo group at the same period of follow up;

${ }^{\mathrm{c}}$ Mean of the two values recorded before the glucagon and the breakfast tests on two consecutive days 


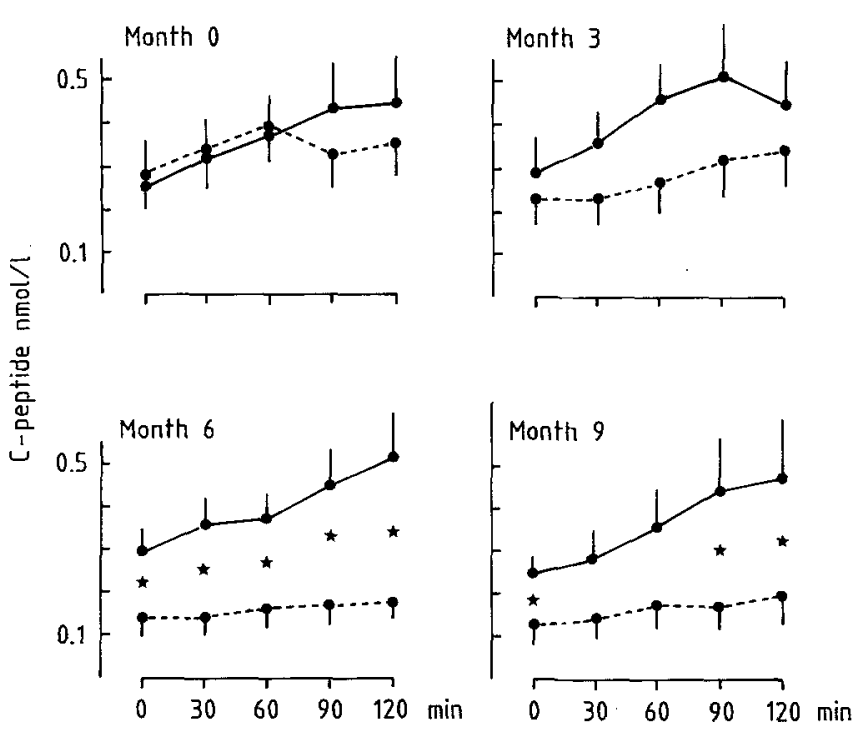

Fig.3. Mean ( \pm SEM) values of C-peptide level during the breakfast test at entry, 3, 6 and 9 months in the nicotinamide (straight line) and the placebo (dotted line) groups. Asterisks denote significance at the 0.05 level

\section{Discussion}

The patients studied here presented with unequivocal insulin dependency of abrupt onset. The prevalence of HLA DR3 and/or 4 antigen was similar to that observed among Type 1 diabetic patients in our geographical area [13]. On an average of two years after diagnosis ICA were persisting among $40 \%$ of the patients a percentage similar to that reported by Irvine et al. [18]. They may be considered as classic Type I diabetic patients. However, their mean age may appear rather high. This is probably due to the facts that children were excluded and that the selection was made on the presence of stimulated C-peptide level higher than $0.1 \mathrm{nmol} / 1$, a feature more frequently observed after 1 to 2 years of diabetes in adults than in adolescents [16, 19].

A gradual decrease in the C-peptide levels of the Type I diabetic patients receiving the placebo was recorded over the 9 month follow-up. This finding was in agreement with the values observed in a recent cross sectional study [16]. Conversely in nicotinamidetreated patients fasting, or glucagon-stimulated, C-peptide levels were constant over the 9 month period. There is no reason to suggest that this stability could be attributed to a decrease in C-peptide metabolic clearance. Indeed, kidney function as judged by the plasma creatinine level, was unaltered. More importantly, an increase in C-peptide reading recorded $5 \mathrm{~min}$ after the glucagon injection can only be accounted for by an increase in secretion and not by an extended plasma half-life. At 6 and 9 months, diabetic patients treated with nicotinamide were better controlled than those receiving the placebo and a recovery of residual insulin secretion has been shown to occur when diabetes is well controlled. However, since this recovery lasts only a few days [20], it cannot account for the differences observed between the two groups in the present study. Thus, it is reasonable to assume that the stable C-peptide levels noted here are due to a preservation of residual insulin secretion resulting from nicotinamide treatment. It must be pointed out, however, that the patients studied were adults. It has been shown that on average, the lower the age of diabetes onset, the faster the loss of C-peptide secretion [21]. Therefore, these results cannot be applied to diabetic children in whom the B-cell destruction is probably more rapid. We recorded a similar finding, i.e. preservation of C-peptide secretion (and consequently a prolonged remission) in a study of newly diagnosed Type 1 diabetic patients treated with the same doses of nicotinamide [11]. In case reports involving patients treated with large doses of nicotinamide, generally for dermatologic disorders, various effects on diabetes have been described. In one case, insulin requirement decreased from 72 to $55 \mathrm{IU}$ per day and in another, the glycaemia level increased to $26 \mathrm{mmol} / 1$ and returned to normal when the treatment was discontinued [22].

Our results are in agreement with the results of animal studies. It has been shown that treatment with nicotinamide prevents the induction of toxic diabetes by streptozotocin in the rat [2]. This finding has since been widely corroborated [23]. It must, however, be pointed out that in two accidental human poisonings with Vacor (a rodenticide), which is structurally related to streptozotocin, treatment with nicotinamide at a dose of $2 \mathrm{~g} /$ day beginning at 9 and $14 \mathrm{~h}$ after exposure, failed to prevent diabetes [24]. Large doses of nicotinamide $(0.5 \mathrm{~g} / \mathrm{kg})$ stopped streptozotocin-induced insulitis [5] and the development of diabetes (and insulitis) in the NOD mice when given before the time when diabetes usually occurs [4]. Finally in the $90 \%$ pancreatectomized rat nicotinamide treatment $\left(0.5 \mathrm{~g} \cdot \mathrm{kg}^{-1} \cdot \mathrm{day}^{-1}\right)$ greatly improved diabetic symptoms and induced a B-cell regeneration as shown by markedly enlarged islets comprising mainly of B cells [3].

On the whole these results strongly suggest that nicotinamide helps $B$ cells ward off toxic or lymphocyte attacks and promotes regeneration of B cells. Several explanations have been proposed to account for this effect in animals. In Okamoto's model [25] various agents such as streptozotocin or alloxan or immune aggression can cause DNA strand breaks in B cells. This anomaly activates poly (ADP-ribose) synthetase which leads to consumption of NAD and thus, depletion of the islet NAD. This deficiency results in an inhibition of protein synthesis including proinsulin [26] and cell necrosis. In effect, the B cell seems to be self-destructive in a suicidal attempt to repair the damaged DNA. Thus, poly (ADP-ribose) synthetase inhibitor can have prophylactic effect by blocking NAD consumption so as to prevent cell necrosis.

Another important animal study finding is that nicotinamide stimulated DNA synthesis in cultured murine islet cells [27]. This observation is pertinent to the induc- 
tion of proliferation of intact B cells in $90 \%$ pancreatectomized rats [3]. It has been suggested that poly (ADPribose) synthetase may play a regulatory role in restricting $B$ cell replication with a relief of inhibition being provided by the enzyme inhibitors [25].

In our study patients treated with nicotinamide were better controlled than those receiving the placebo with the same or lower doses of insulin. It is likely that this greater efficiency resulted from a preservation of insulin secretion which has been shown to be beneficial for diabetes control and stability [28, 29].

We did not observe any significant side effects. Since nicotinamide and nicotinic acid have been used in the treatment of schizophrenia, psychiatric literature is a good source of information concerning the side effects of these drugs. In two series including 315 and 982 patients treated with doses ranging from 3 to $12 \mathrm{~g}$ daily, only rashes, vomiting and headaches were noted. No cutaneous reaction was observed. The incidence of liver toxicity is very low: one case out of 6,000 , reported at a meeting of the American Schizophrenia Foundation [8]. However, Winter and Boyer [30] reported a 35year-old schizophrenic man who developed reproducible and reversible hepatic toxicity following a daily dose of $9 \mathrm{~g}$ of nicotinamide. We did not observe any change in liver function test data. Moreover, among the 1,119 subjects who received $3 \mathrm{~g}$ nicotinic acid daily for 5 years or more in the Coronary Drug Project [9], only a slight elevation of serum GOT and alkaline phosphatase were noted. Thus, nicotinamide at a dose of $3 \mathrm{~g} /$ day would appear to be reasonably safe although regular liver function testing is advisable.

The lipid lowering effect of nicotinic acid is well known. At a dose of $3 \mathrm{~g}$ daily it reduces plasma cholesterol and triglyceride levels by $10 \%$ and $19 \%$ respectively [9]. Nicotinamide does not appear to have the same effect since we observed no change in lipid levels in our patients.

Since combined administration of streptozotocin or alloxan and nicotinamide reportedly induces islet cell tumours in rats [31], the possibility that nicotinamide is carcinogenic must also be considered. When administered alone, i.e. without nicotinamide, both streptozotocin and alloxan may cause B cell cancer [31]. Although this effect is potentiated by nicotinamide, no evidence has been found to suggest that nicotinamide treatment alone is an oncogenic agent in animals, even NOD mice (Okamoto, personal communication). Thus, nicotinamide may be considered as a cocarcinogen with other agents but not as a carcinogen by itself. Human Type 1 diabetes is not associated with islet cell tumours. Fewer than ten cases of islet cell tumours have been reported in documented Type 1 diabetic patients. Thus, the various environmental factors underlying the pathogenesis of Type 1 diabetic patients do not seem to have B-cell oncogenicity. There is therefore no argument to prohibit the careful trial use of nicotinamide in Type 1 diabetic patients.
Nicotinamide seems to have a protective effect on residual insulin secretion in Type 1 diabetic patients. Such a treatment is apparently devoid of serious side effects. Therefore, it is possible to think that nicotinamide or related substances may have a place in association with other therapeutic agents in preventing diabetes in predisposed subjects, to facilitate induction of remission in newly diagnosed diabetes or to preserve a residual insulin secretion which is known to be a factor improving diabetes control. Future trials may help to answer these questions.

Acknowledgements. The Laboratoire Astra-France generously provided the nicotinamide and the placebo tablets. We thank R. Sambuc and $\mathrm{X}$. Thirion for their help with the statistical analysis.

\section{References}

1. Eisenbarth GS (1986) Type I diabetes mellitus. A chronic autoimmune disease. N Engl J Med 314: 1360-1368

2. Stauffacher W, Burr I, Gutzeit A, Beaven D, Velinsky J, Renold AE (1970) Streptozotocin diabetes: time course of irreversible Bcell damage; further observations on prevention by nicotinamide. Proc Soc Exp Biol Med 133: 194-200

3. Yonemura Y, Takashima T, Miwa K, Miyazadi I, Yamamoto $H$, Okamoto H (1984) Amélioration of diabetes mellitus in partially depancreatized rats by poly (ADP-ribose) synthetase inhibitors. Evidence of islet B-cell regeneration. Diabetes 33: 401-404

4. Yamada $\mathrm{K}$, Nonaka $\mathrm{K}$, Hanafusa T, Miyazaki A, Toyoshima $\mathrm{H}$, Tarvis S (1982) Preventive and therapeutic effects of large dose nicotinamide injections on diabetes associated with insulitis. An observation in non obese diabetic (NOD) mice. Diabetes 31: 749-753

5. Rossini AA, Like AA, Chick WL, Appel MC, Cahill GF (1977) Studies of streptozotocin-induced insulitis and diabetes. Proc Nat Acad Sci USA 74: 2485-2489

6. Nomikos IN, Prowse SJ, Carotenuto P, Lafferty KJ (1986) Combined treatment with nicotinamide and desferrioxamine prevents islet allograft destruction in NOD mice. Diabetes 35: 1302-1304

7. Hawkins DR (1968) Treatment of schizophrenia based on the medical model. J Schizophr 2: 3-10

8. Hoffer A (1969) Safety, side effects and relative lack of toxicity of nicotinic acid and nicotinamide. Schizophrenia 1:78-87

9. The Coronary Drug Project Research Group (1975) Clofibrate and Niacin in coronary heart disease. $\mathbf{J}$ Am Med Assoc 231: 360-381

10. Ma A, Medenica M (1983) Response of generalized granuloma annulare to high dose Nicotinamide. Arch Dermatol 119:836-839

11. Vague P, Vialettes B, Lassmann-Vague V, Vallo JJ (1987) Nicotinamide may extend remission phase in insulin-dependent diabetes. Lancet I: $619-620$

12. Mirouze J, Selam JL, Pham TL, Mendoza A, Orsetti A (1978) Sustained insulin induced remissions of juvenile diabetes by means of an artificial pancreas. Diabetologia 14: 223-227

13. Vague P, Vialettes B, Lassmann V, Moulin JP, Mercier P (1985) Sustained initial remission induced by intensive insulin treatment in type I diabetes. Possible role of the genetic background. Acta Diabetol Lat 21: 295-304

14. Mistura L, Beccaria L, Meschi F, Flores D'Arlais A, Pellini C, Puzzovio M, Chiumello $G(1987)$ Prednisone treatment in newly diagnosed type I diabetes children: 1-year follow-up. Diabetes Care 10: $38-43$

15. Sochett EB, Daneman D, Clarson C, Ehrlich RM (1987) Factors affecting and patterns of residual insulin secretion during the first 
year of Type 1 (insulin-dependent) diabetes mellitus in children. Diabetologia 30: 453-459

16. The DCCT Research Group (1987) Effects of age, duration and treatment of insulin-dependent diabetes mellitus on residual Bcell function: observation during eligibility testing for Diabetes control and complications trial (DCCT). J Clin Endocrinol Metab 65: $30-36$

17. Kaneto T (1974) Radioimmunoassay of human proinsulin C-peptide using synthetic human connecting peptide. Endocrinol Jpn 21: $141-150$

18. Irvine WJ, Mc Callum CJ, Gray RS, Campbell CJ, Duncan LJP, Farquhar JW, Vaughan EH, Morris PJ (1977) Pancreatic islet cell antibodies in diabetes mellitus correlated with the duration and type of diabetes, coexistent autoimmune disease and HLA type. Diabetes 26: 138-147

19. Madsbad S, Faber OK, Binder C, McNair P, Christiansen C, Transbol I (1978) Prevalence of residual Beta-cell function in insulin dependent diabetics in relation to age at onset and duration of diabetes. Diabetes 27 [Suppl 1]: 262-264

20. Madsbad S, Krarup T, Regeur L, Faber OK, Binder C (1981) Effect of strict blood glucose control on residual B-cell function in insulin-dependent diabetics. Diabetologia 20: 530-534

21. Wallensteen M, Dahlquist G, Persson B, Landin-Olsson M, Lernmark $\AA$, Sundkvist $G$, Thalme B (1988) Factors influencing the magnitude, duration and fall of B-cell function in Type 1 (insulindependent) diabetic children followed for two years from their clinical diagnosis. Diabetologia 31: 664-669

22. Mandfield-Jones S, Jones SK, Peach RDG (1987) Nicotinamide treatment in diabetes. Br J Dermatol 116: 277

23. Dulin WE, Wyse DM (1969) Studies on the ability of compounds to block the diabetogenic activity of streptozotocin. Diabetes 18 : 458-466

24. Pont A, Rubino JM, Bishop D, Peal R (1979) Diabetes mellitus and neuropathy following vacor ingestion in man. Arch Intern Med 139: 185-187
25. Okamoto H (1981) Regulation of proinsulin synthesis in pancreatic islets and a new aspect to insulin dependent diabetes. Mol Cell Biochem 37: 43-61

26. Uchigata $Y$, Yamamoto $H$, Nagai $H$, Okamoto $H$ (1983) Effect of poly (ADP-ribose) synthetase inhibitor administration to rats before and after injection of alloxan and streptozotocin on islet proinsulin synthesis. Diabetes 32: 316-318

27. Sandler S, Andersson A (1986) Long-term effects of exposure of pancreatic islets to nicotinamide in vitro on DNA synthesis, metabolism and B-cell function. Diabetologia 29: 199-202

28. Sjöberg S, Gunnarson R, Gjötteberg M, Lefvert AK, Persson A, Östman J (1987) Residual insulin production, glycaemic control and prevalence of microvascular lesions and polyneuropathy in long-term Type 1 (insulin-dependent) diabetes mellitus. Diabetologia 30: 208-213

29. Fukuda M, Tanaka A, Tamara $Y$, Ikegami H, Yamamoto $Y$, Kumamara Y, Smima K (1988) Correlation between minimal secretory capacity of pancreatic B-cells and stability of diabetic control. Diabetes 37: 81-88

30. Winter SL, Boyer JL (1979) Hepatic toxicity from large doses of vitamin B 3 (Nicotinamide). N Engl J Med 283: 1180-1182

31. Yamagami $T$, Miwa $A$, Takasawa $S$, Yamamoto $H$, Okamoto $H$ (1985) Induction of rat pancreatic B-cell tumors by the combined administration of streptozotocin or alloxan and poly (ADPribose) synthetase inhibitors. Cancer Res 45: 1845-1849

Received: 12 December 1988

and in revised form: 9 March 1989

Dr. P. Vague

CHU Timone

264, rue Saint-Pierte

F-13385 Marseille Cédex

France 